then the assembly deforms in a pure shear mode and slip occurs at all contacts.

In Fig. 1 the simple shear mechanisms have been redrawn with the initial contact points $(P, Q, R$ and $S$ ) connected to the centres of their respective spheres. For slip to occur at $Q$ and $R$ but not at $P$ and $S$, the points on the spheres which are initially in contact at $\mathbf{P}$ and $\mathbf{S}$ must remain in contact after failure. Figure 1 shows that, for plane strain deformation, this condition is satisfied if one set of close-packed planes does not rotate. However, if there is lateral expansion in both the $x$ and $y$ directions, even though one set of close-packed planes may not rotate, slip occurs at $P$ and $S$ as well as at $Q$ and $R$. This is clearly shown in Fig. 1 for the case of axisymmetric compression.

Hence, gap formation at both $U$ and $T(a \neq 0$, $b \neq 0$ ) is possible only if slip occurs at all contacts and, for the no spin condition, this means that the stress and strain-increment tensors must be coaxial. In the plane strain case, however, as the close-packed planes remain close-packed, slip need not occur at $P$ and $S$ and a range of non-coaxial solutions is possible, including the lowest solution provided by Rennie (1959).

As the solution is related to the current coordinates of the spheres, equation (1) must be regarded as a strain-rate, or strain-increment tensor, not as a strain tensor.

\section{REFERENCES}

Parkin, A. K. (1965). On the strength of packed spheres. J. Aust. Math. Soc. 5, 443-452.

Rennie, B. C. (1959). On the strength of sand. J. Aust. Math. Soc. 1, 71-79.
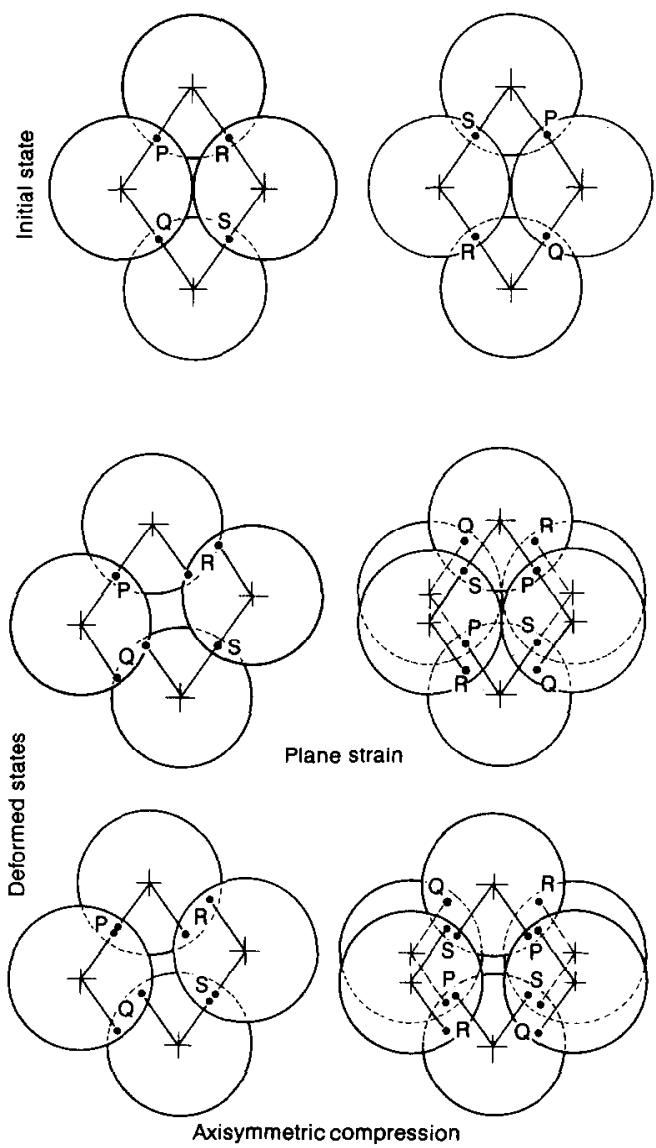

Fig. 1. Simple shear mechanisms

\title{
A comparison of the stiffness of the chalk at Mundford from a seismic survey and a large scale tank test
}

\author{
C. P. ABBISS (1979). Géotechnique 29, No. 4, 461-468
}

\section{Professor P. Ullidtz, Institut for veje, trafik og byplan, Denmark}

In the Paper two methods of in situ determination of stiffness as a function of depth are mentioned. One is based on large-scale plateloading tests and the other on in situ measurement of strains at various depths below a test tank. The Paper then describes a third and less costly method using a seismic survey. To these three a fourth method may be added. In addition to being inexpensive, this method has the advantage that the moduli are determined at a realistic stress level which is very important when the materials are non-linear elastic.

When a point load $P$ is applied to the surface of an elastic half-space, the modulus $E$ of the material may be calculated from the deflexion $d_{r}$ at distance $r$ (Boussinesq, 1885)

$$
E=\left(1-v^{2}\right) P /\left(\pi r d_{r}\right)
$$

where $v$ is Poisson's ratio (see Fig. 1).

The compression (or tension) of the material between the surface and a depth equal to the distance $r$ from the point load will be approxi- 


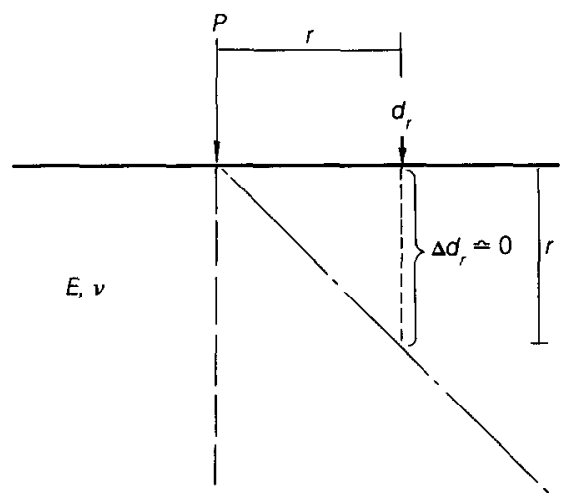

Fig. 1. Point load on elastic half-space

mately zero (for Poisson's ratio equal to approximately $0-39$ it will be zero).

For a layered structure the modulus calculated from equation (1) is the surface modulus $E_{0}$, i.e. the modulus that an elastic half-space should have to give the same deflexion for the same load. In a material where the modulus is increasing with depth the surface modulus will correspond to a depth approximately equal to $r$, because the stress distribution in such a material is reasonably close to Boussinesq's (Ullidtz, 1976). The surface modulus is therefore a sort of weighted average of the moduli of the materials below the depth $r$.

For a layered structure the modulus of the lowest, semi-infinite material is equal to the surface modulus at distances larger than the depth to this material. For the remaining layers the moduli may be found from an iterative calculation using Boussinesq's equations. This may be carried out very quickly on a programmable pocket calculator. If the modulus increases proportionally to the depth to a power of $n$ (i.e. $E \propto z^{n}$ ), then the modulus of a certain depth is equal to the surface modulus corresponding to that depth (distance) divided by $(1+n)$. A similar relationship may be used when the soil is non-linear elastic. If the load is distributed over a circular area with radius $a$, Boussinesq's equation may still be used for distances larger than $1 \frac{1}{3} a$ from the centre of the load.

The method was developed in order to determine the layer moduli of road pavements from non-destructive measurements (Ullidtz, 1977). A simple transportable falling weight deflectometer, giving a load pulse of $25 \mathrm{~ms}$ duration with a peak magnitude of $50 \mathrm{kN}$, is used to apply the load, and geophones arc used to measure the deflexions at various distances. The dynamic loading may be used because only the moduli of materials within a shallow depth $(1-2 \mathrm{~m})$ are of interest. The results may be interpreted using the method of equivalent thicknesses (Odemark,
1949; Ullidtz \& Busch, 1979) or by means of diagrams worked out for cases of linear and nonlinear subgrades (Ullidtz, 1977).

In order to determine the moduli at larger depths, either a dynamic loading of longer duration or a static loading must be used. This will make the measurement of the deflexions more complicated, but inclinometers could possibly be used.

Valuable information with respect to the variation of moduli with depth is to be obtained from the deflexion basin. Determination of the deflexion basin is much easier and less expensive than measuring the strains or carrying out plateloading tests at different depths, and it is possible to obtain much more realistic stress levels than with seismic methods. Calculations of the moduli from the deflexions are usually quite simple.

\section{REFERENCES}

Boussinesq, J. (1885). Application des potentiels à l'étude de l'équilibre el du mouvement des solides élastique.

Odemark, N. (1949). Undersøkning av elasticitetsegenskaperna hos olika jordarter samt teori for beräkning av belägninger enligt elasticitetsteorin. Statens Väginstitut, Meddelande 77.

Ullidtz, P. (1976). Some simple methods of determining the critical strains in road structures. Thesis, Technical University of Denmark.

Ullidtz, P. (1977). Overlay and stage by stage design. Proc. 4th Int. Conf. Structural Design of Asphalt Pavements, Ann Arbor, Vol. 1.

Ullidtz, P. \& Busch, C. (1979). Laboratory testing of a fullscale pavement. Paper presented at the 58 th Annual Meeting of the Transportation Research Board, Washington, DC.

\section{Author's reply}

The method described by Professor Ullidtz is interesting and is related to the measurements in the Paper. The observed deflexions of the surface bowl around the tank were less than the deflexions calculated from the Boussinesq theory and the $E$ value from equation (1) of Professor Ullidtz does increase with distance $r$ from the tank centre, with $r$ greater than the tank radius. This effect is also shown by the profile calculated by the finite element program (Burland, Sills \& Gibson, 1973).

There would appear to be a minimum distance $r_{\min }$ below which the formula ceases to be valid, because $E$ tends to infinity as $r$ tends to zero for finite deflexion $d_{r}$. However, this may not be a problem in practice.

The suggestion that $\Delta d_{r} \simeq 0$ is borne out by stress distribution curves and shows neatly that the deflexion of the surface at a distance $r$ is approximately equal to that of the material in a cone below a depth $r$ as indicated by Fig. 1 .

Professor Ullidtz's contribution emphasizes that increase of stiffness with depth is important for 
calculation of settlements of larger foundations and this is demonstrated by an analytical study (Brown \& Gibson, 1979). This shows that the settlements are less than for the elastic half-space, by an amount that increases with the size of the foundation and with the rate of increase of stiffness with depth.

The modulus used in such calculations should be appropriate for the strain and time involved. The dependence on these variables is being studied and I believe that there may be a satisfactory mathematical model that will relate moduli measured under different conditions. Another dynamic method of measurements will be helpful.

\section{REFERENCES}

Brown, P. T. \& Gibson, R. E. (1979). Surface settlement of a finite elastic layer whose modulus increases linearly with depth. Int. J. Num. Anal. Meth. Geomech. 3, 37-47.

Burland, J. B., Sills, G. C. \& Gibson, R. E. (1973). A field and theoretical study of the influence of non-homogeneity on settlement. Proc. 8th Int. Conf. Soil Mech. Fdn Engng, Moscow. BRE Current Paper 32/73.

\title{
A one point cone penetrometer liquid limit test?
}

\author{
C. R. I. CLAYTON and A. W. JUKES (1978). Géotechnique 28, No. 4, 469-472
}

\section{D. Joyce, South Yorkshire County Council}

The test factors obtained by the Authors, and quoted in Table 1 for all soil, are virtually identical with figures obtained in South Yorkshire in 1977 even though the South Yorkshire figures were based on a sample size less than one fifth of that of the Authors and no doubt on different soils. It was also found that the reproducibility and accuracy of results using a one point cone penetrometer assessment were superior to those obtained by the one point Casagrande method. Of the liquid limits determined by the one point cone penetrometer test $94 \%$ fell within $\pm 2 \%$ of the four point test result. In view of the work that has now been carried out and the substantial cost benefits, I feel it would be appropriate for the British Standards Institution to consider the adoption of a one point cone penetrometer test and to investigate the possible use of the cone penetrometer in the determination of the plastic limit.

\section{A natural compression law for soils (an advance on $e-\log p^{\prime}$ )}

\author{
R. BUTTERFIELD (1979). Géotechnique 29, No. 4, 469-480
}

\section{Dr B. Schmidt, Parsons Brinckerhoff, San Francisco}

The Author expands elegantly on the traditional linear $e-\log p^{\prime}$ curves. Using natural strain rather than conventional strain straightens out nonlinearities often found at great strains, without greatly affecting stress-strain relations for small strains. The simplicity of the Author's concept is attractive, but the implication that it may be applied to a variety of soils, including perhaps granular soils, and to rebound and reload curves, requires further examination.

The example plots appear to show good straight-line relations for rebound and reload curves, although they are only slightly better than on standard plots. However, there are many examples of clay soils (e.g. Hansen \& Mise, 1964) showing rebound and reload curves that can be fitted only to far more complex mathematical expressions.

The relationship $d(\ln v)=-\mathbb{C} d\left(\ln p^{\prime}\right)$ works only when $m_{\mathrm{v}}=\mathbb{\Phi} / p^{\prime}$. For granular soils, this relationship does not work; here, another more general approach must be taken, such as that described by Janbu (1963). Janbu proposed a soil compression modulus that depends on stress level

$$
K=1 / m_{\mathrm{v}}=d p / d \varepsilon=c p^{1-s}
$$

For $s=1$, this is equivalent to Hooke's law; for $s=0$, it leads to

$$
d p / p=c d \varepsilon=-c d v / v
$$

